\title{
Da periferia insular às fronteiras do império: colonos e recrutas dos Açores no povoamento da América
}

José Damião Rodrigues*

Resumo. No contexto português, as gentes das ilhas atlânticas foram, por mais de uma vez, um recurso importante da monarquia para povoar e defender outras zonas periféricas do império português. Neste artigo, apresentamos as linhas gerais do povoamento do Norte (Pará e Maranhão) e do Sul (Santa Catarina e Rio Grande do Sul) do Brasil nos séculos XVII e XVIII com recurso a levas de colonos — os "casais" - e de recrutas originários dos Açores, um processo apenas interrompido pela independência do Brasil.

Palavras-chave: Migrações atlânticas. Povoamento. Colonos. Recrutas. Brasil. Açores.

Ao longo da história, os territórios insulares sempre desempenharam importantes funções, mas terá sido sobretudo a partir do século XV, com a expansão europeia e o processo de interligação de continentes, que os arquipélagos se afirmaram como "natural bridges between oceanic worlds." "Não seria necessário recuperar aqui a interpretação do historiador francês Fernand Braudel, no seu clássico estudo sobre o Mar Mediterrâneo, ao reconhecer que, embora pudesse existir um "factor de isolamento" superior a qualquer outro espaço físico no caso de as ilhas estarem isoladas, quando posicionadas em locais de circulação e de passagem de circuitos de navegação, as ilhas constituíam elementos de ligação abertos para o

\footnotetext{
* Universidade dos Açores/CHAM.
} 
Da periferia insular às fronteiras do Império...

mundo exterior, estando muitas vezes menos isoladas do que certas regiões continentais das montanhas e do interior ${ }^{2}$.

Neste contexto, as ilhas e os arquipélagos da Macaronésia constituíram "corridors through which institutions, economic patterns, and people of the Mediterranean region began to pass into the Atlantic basin"3. E precisamente devido à sua centralidade na construção e articulação do mundo atlântico não podemos aceitar de forma acrítica ou essencialista a visão das ilhas como um espaço perdido e isolado, como nos recorda ainda o citado John Gillis: "There was nothing at all insular about the islands or the islanders"4. Se é certo que devemos efectuar uma avaliação caso a caso, considerar os contextos históricos, de um modo geral será possível defender que o carácter "remoto" das ilhas desenvolveu-se apenas no século XIX, acompanhando as mudanças que se operaram no sistema de transportes e o nascimento de uma representação romântica das ilhas.

A partir deste quadro, o nosso objectivo é destacar o papel que os habitantes dos Açores desempenharam na colonização e defesa do litoral sul da América portuguesa no século XVIII por via de dois processos migratórios, o dos "casais" e o das "levas" de recrutas.

Em 1680, a fundação da colónia do Sacramento na margem norte do Rio da Prata, autêntica porta de entrada para o contrabando entre o Rio da Prata e o Perú, comprovou a importância estratégica que a coroa portuguesa atribuía à bacia platina. Os Castelhanos haviam atingido pela primeira vez a região em 1516, mas foi a segunda fundação de Buenos Aires, em 1580, que assinalou a afirmação definitiva das pretensões dos Áustrias à posse desse espaço. A instalação de uma colónia portuguesa nas margens do Prata, cem anos mais tarde, em frente a Buenos Aires, representou, pois, um perigo para os objectivos da Monarquia Católica, abrindo-se assim um foco de tensão em torno dos limites dos territórios ibéricos na América do Sul que marcou a política americana das monarquias portuguesa e espanhola entre os finais do século XVII e a década de 1770.

A descoberta de ouro no sertão paulista na última década de Seiscentos, "prometendo riquezas e felicidades ao reino de V. Magde.", nas palavras de D. João de Lencastre em carta dirigida a D. Pedro II, em 1701, confirmou a "ocidentalização" do império que se desenhara no século XVII e a importância do Brasil no contexto 
imperial português ${ }^{5}$ e o realinhamento político da dinastia brigantina operado no contexto da Guerra da Sucessão de Espanha e materializado nos tratados celebrados em Março e Dezembro de 1703 consagrou em definitivo a opção atlântica da monarquia ${ }^{6}$. Todavia, a conjuntura da guerra, que se projectou no Atlântico com ataques castelhanos à praça do Sacramento — abandonada em 1705 - e franceses ao Rio de Janeiro (1710 e 1711), estes integrados num claro projecto de conquista da cidade e de controlo do comércio aurífero ${ }^{7}$; as revoltas na colónia e os conflitos entre colonos, como a Guerra dos Emboabas (1707-1709) e a dos Mascates (1710-1711), demonstraram que era necessário reforçar a autoridade metropolitana no Estado do Brasil e providenciar a ocupação e defesa do litoral, de modo a evitar quer este tipo de ataques, quer o comércio de estrangeiros.

Em relação a este trato, o memorialista José Soares da Silva dava conta nas suas notas, em julho de 1710, de que um navio de licença chegara a Lisboa ido da Baía levando a notícia de que os Ingleses faziam o seu comércio na América portuguesa enviando navios à Baía, ao Rio de Janeiro e a Pernambuco e regressando à Europa com ouro, açúcar e tabaco. E concluía o seu registo a este propósito expressando o receio de que, caso tão danoso negócio continuasse, estaria em risco a posse do Brasil, pois, conforme escreveu, "com a demora se faz irreparável, como tambem a perda deste nosso Reyno sem a utilidade daquellas Conquistas". Anos mais tarde, Sebastião da Rocha Pita confirmaria estas palavras, ao denunciar os "grandes insultos e roubos de piratas nos seus mares, tomando vários navios que saíam dos seus portos ou a eles iam, e com maior porfia depois que se descobriram as Minas do Sul."

Foi pois perante a necessidade de garantir a projecção da soberania portuguesa nas regiões sul-brasileiras que a monarquia joanina recorreu à presença de contingentes militares e à fixação de casais ilhéus, política, de resto, que a coroa portuguesa tinha já praticado no século XVII em relação ao Maranhão e ao Pará ${ }^{10}$. Com efeito, no século XVIII, e apesar das ordens régias em contrário — publicadas em 1709, 1711, 1713, 1720 e $1744^{11}$ —, a emigração portuguesa para o Brasil aumentou e contou com o contributo das gentes insulanas. Não obstante a publicação da lei de 20 de março 
Da periferia insular às fronteiras do Império...

de 1720, com aplicação nas ilhas, que surgiu como um entrave à livre circulação de homens entre o reino e o Brasil, ao longo da primeira metade de Setecentos a coroa continuou a promover a saída de "casais" ilhéus para a América do Sul com o objectivo de povoar e defender as regiões fronteiriças meridionais e setentrionais, optando por nova estratégia, a dos recrutamentos militares nos Açores, a partir da segunda metade do século XVIII. É então sobre estes dois tipos de fluxos migratórios rumo ao Atlântico Sul que focaremos a nossa atenção.

Ainda durante o período crítico da Guerra da Sucessão de Espanha e face à ameaça de um ataque ao Rio de Janeiro e outros territórios da América portuguesa, por ordens régias de 8 de abril e 26 de setembro de 1708, foi determinada a recruta na Terceira e nas "ilhas de baixo" de 200 homens destinados à capitania do Rio de Janeiro e de 120 ao Maranhão ${ }^{12}$. Tal como fizera no passado e voltaria a fazer ao longo de Setecentos, a coroa recorria ao alistamento de recrutas insulanos numa conjuntura difícil.

Nesse mesmo ano, os Franceses, comandados por René Duguay Trouin, atacaram a ilha de São Jorge e saquearam as vilas de Velas e da Calheta, provocando grande apreensão nas ilhas, sobretudo na Terceira ${ }^{13}$. O ataque francês revelou as fragilidades das estruturas defensivas existentes nas ilhas açorianas e a coroa reagiu enviando aos Açores, em 1709, António do Couto de Castelo Branco (1669 1742) com a missão de inspeccionar o estado das fortificações e das guarnições pagas, bem como das milícias, nas ilhas dos grupos central e ocidental $1^{14}$. Na sua descrição, o inspector régio deu conta da situação encontrada, mas também se pronunciou quanto à possibilidade de se retirar gente das ilhas: na Graciosa, e a requerimento dos povos, 200 casais, "porque a gente que ha é muita, e pouco o em que se occupem e com que vivam"; e, no Pico, também "alguns casaes, por ter mais gente da com que pode" ${ }^{\prime 15}$. Retenhamos esta argumentação: face à pobreza e à sobrepopulação das ilhas, a emigração constituía uma resposta adequada, sobretudo quando podia configurar-se como um serviço da monarquia. Importa aqui sublinhar que, mais do que uma questão de ordem socioeconómica, o argumento da sobrepopulação apresentava-se como de natureza eminentemente biopolítica ${ }^{16}$.

Anos 90, Porto Alegre, v. 17, n. 32, p. 17-43, dez. 2010 
Finda a Guerra da Sucessão de Espanha com a assinatura dos vários tratados bilaterais de Utrecht e de Rastatt (1713-1715) ${ }^{17}$, a Nova Colónia do Sacramento, abandonada em 1705, foi recuperada por Portugal, conseguindo a diplomacia lusa que a colónia fosse reconhecida por Espanha como o ponto mais meridional do domínio português nas Américas. E, após a restituição da praça, em 1716, o Conselho Ultramarino tratou de promover a ocupação do território com o recurso a casais de Trás-os-Montes e dos Açores ${ }^{18}$. No entanto, apesar do acordado em Utrecht, no terreno as demarcações revelaram-se de difícil execução, conforme atesta a correspondência trocada entre o governo da colónia e a Corte nos anos de 1718 e $1719^{19}$, e a necessidade de fixar população continuou a fazer sentir-se.

Entretanto, a conjuntura que medeia entre a formação da Quádrupla Aliança, em 1718, opondo-se às ambições de Filipe V que, em 1720, acabaria por integrar a mesma, renunciando ao trono francês - , e a assinatura do Tratado de Cambrai, a 27 de março de 1721, confirmando a nova aliança franco-espanhola, revelou-se preocupante para os interesses portugueses na América do Sul ${ }^{20}$. Neste quadro, a crise sísmica e vulcânica que assolou a ilha do Pico nos anos de 1717, 1718 e 1720 forneceu uma nova oportunidade para o Conselho Ultramarino promover o povoamento português no Brasil meridional, apoiando a súplica das populações atingidas pelos efeitos da crise, que requeriam passar às "partes do Brazill". Em consulta de 31 de outubro de 1720, a posição do Conselho Ultramarino acerca da representação dos picoenses é exposta de forma clara: o requerimento devia ser atendido não apenas por ser obrigação dos reis acudir à necessidade dos seus vassalos e remediar o seu sofrimento, mas, "muito principalmente", quando o "remédio" proposto

[...] he o que maes conuem ao seruisso de vossa magestade e defesa e bom gouerno da monarchia por ser preciso e muito necessario que se pouoe a costa do sul [riscado] que corre do porto de Santos para o sul athe a Noua Colonia, porque contem esta costa os milhores portos de toda a America portugueza e podendo por esta cauza recear se justamente que os navios da Europa uendo as desemparadas as queirão ocupar. $^{21}$

Anos 90, Porto Alegre, v. 17, n. 32, p. 17-43, dez. 2010 
Da periferia insular às fronteiras do Império...

Para os conselheiros, em nome da segurança e do aumento do Estado do Brasil, era urgente mandar povoar todos os portos até aos rios de São Francisco Xavier e Rio Grande de São Pedro e ainda povoar a ilha de Santa Catarina, cujos moradores, em reduzido número, "uiuem a medo dos piratas, [riscado] que os obrigão a fornecer lhe os mantimentos e agoada" 22 , palavras que parecem antecipar as que Sebastião da Rocha Pita registará na sua história. Assim, entre 1720 e 1723, o Conselho Ultramarino procurou organizar, com a colaboração do corregedor dos Açores e a das câmaras locais, o alistamento de casais que deveriam rumar ao Brasil meridional ${ }^{23}$.

O processo não foi célere nem fácil. Em carta de 22 de agosto de 1722, o corregedor dos Açores escrevia a D. João V informando-o de que, em obediência às ordens emanadas da Secretaria de Estado, tratara de escrever às câmaras picoenses, pedindo-lhes as listas das pessoas que se haviam voluntariado para irem para a Nova Colónia do Sacramento e que "estauão de animo" em relação à viagem, na medida em que a Fazenda Real procurava evitar as despesas do transporte com aqueles que se revelassem menos motivados. E, de facto, enquanto as listas iniciais registavam mais de 1.700 indivíduos, as relações recebidas pelo magistrado no Verão de 1722 indicavam um total de 1.432 pessoas, divididas em 261 casais $^{24}$.

Para as gentes do Pico, que trabalhavam uma terra pobre e insuficiente para o seu sustento, os flagelos da natureza agravavam a luta quotidiana pela sobrevivência, pelo que a hipótese brasileira surgia como uma fuga à pobreza. Com efeito, ao chegarem à colónia do Sacramento, transportadas à custa da Fazenda Real, receberiam ainda alfaias agrícolas, sementes e "terras iguais às da Europa" 25 . A importância desta migração, que libertaria a ilha de um número considerável de habitantes, a maior parte dos quais em situação de precaridade social, e, ao mesmo tempo, acudiria à urgência estratégica de povoar o litoral sul-brasileiro, foi resumida por António de Bettencourt da Silveira, encarregado de controlar a feitura das listas das pessoas dispostas a passar à América portuguesa nas jurisdições de Lages e de São Roque. Após descrever a sua actuação, elogiar a "paterna liberalidade" de D. João V e defender ser serviço de Deus que o rei ordenasse às câmaras que embarcassem os casais "pobres e miseráveis" que se não tinham alistado, "dos quoais eu conhesso 
muitos que não tem mais que a noite e o dia", concluía declarando, num enunciado revelador dos princípios da cultura política do Antigo Regime, que os alistados deviam ser obrigados a embarcar "para que focem fazer pouoasonis, con que o real imperio de el rei nosso senhor se augmente, e já que o não podem seruir de outra sorte, o siruam desta, e juntamente não percam huma ocaziam tam [...] a de se milhorarem de estado"26.

A oportunidade oferecida à ilha do Pico levou a que também os oficiais da câmara de Angra decidissem escrever a D. João V, pedindo ao rei que "mande tirar desta Jlha mil pessoas para [a] nova Colonia ou para as Comquistas" 27. Assim, na sequência da vereação de 22 de agosto de 1722, os oficiais representaram ao monarca, em nome do serviço régio, que igual diligência podia ser praticada na Terceira e recordaram a D. João V que aquela se tratava de uma ilha "opulenta de gente sem bens nem razão que possa deficultar o seo embarque" e que todos os anos, nos navios do privilégio, partiam terceirenses em busca de fortuna no Brasil ${ }^{28}$. De igual modo, na vizinha ilha de São Jorge, os oficiais da câmara do Topo produziram uma relação dos moradores que, dada a "pobreza desta villa e sua jurisdiçam", estavam prontos a viajar rumo à Nova Colónia do Sacramento, onde esperavam receber instrumentos de trabalho, armas, casas e uma légua de terra. Entre os alistados, contavam-se lavradores, trabalhadores, moços de servir, vendeiros e oficiais mecânicos ${ }^{29}$.

Porém, em janeiro e fevereiro de 1723, o desembargador António Tavares da Rocha, provedor da Fazenda Real nas ilhas dos Açores, ainda tratava de confirmar quantos eram os casais e as pessoas que "[...] estavão com animo de serem mudados da Ilha do Pico para as costas ou melhores terras da costa do Brazil" ${ }^{30}$. Efectivamente, apesar do transporte correr por conta da Fazenda Real e dos candidatos a colonos terem recebido a garantia de que, uma vez no Brasil, receberiam ferramentas, sementes e terra, a demora no processo de registo, a reavaliação dos riscos por parte de muitos alistados, sobretudo quando se tratava de mulheres e crianças, e o óbito de outros tiveram, como consequência, uma diminuição no número dos casais. No final de um segundo alistamento, que a coroa ordenara para garantir um maior rigor na feitura das listas, estavam arrolados somente 315 picoenses e 194 jorgenses do Topo. 
Da periferia insular às fronteiras do Império...

Alguns naturais do Pico, como um João Machado, ainda se esforçaram por expor a $\mathrm{D}$. João $\mathrm{V}$ que existiam pessoas dispostas a embarcar voluntariamente para as terras da Nova Colónia do Sacramento e, em requerimento anterior a julho de 1723, afirmava estarem alistadas e prontas cerca de 2.000 pessoas "sertaz e bem dispostas para este embarque, alem de outras muntaz em numaro que deixarão de alistarce porque os ministros julgarão ser sufficiente esta rezeinha" 31 . Apelava, pois, para a piedade e a grandeza do rei esperando que este determinasse a efectivação do transporte.

Mas, apesar da entrada de metal precioso no reino, a Fazenda Real enfrentava dificuldades na obtenção do capital necessário para custear as despesas. Em consulta de 20 de outubro de 1723, o Conselho Ultramarino representou a D. João V que a arrecadação de 300.000 cruzados com empréstimos a $5 \%$ se mostrava difícil, propondo os conselheiros - entre os quais avulta o nome de António Rodrigues da Costa — que se recorresse a dinheiro recolhido no Brasil (Minas Gerais, Rio de Janeiro, Baía e Pernambuco) ${ }^{32}$. E, no ano seguinte, o mesmo órgão informava o rei que, embora tivessem sido publicados editais a esse respeito, ninguém aparecera para assegurar o empréstimo que permitiria suportar o transporte das gentes do Pico para o Brasil ${ }^{33}$. A demora revelava-se prejudicial aos interesses estratégicos da monarquia, mas a pressão em torno da disputa territorial na bacia platina diminuiu com a reaproximação entre as coroas ibéricas por ocasião das negociações matrimoniais que culminariam com a "troca das princesas" em janeiro de 1729.

A crise sísmica de agosto de 1729 proporcionou nova ocasião para que os moradores da ilha do Pico, pela voz dos oficiais da câmara das Lages, apelassem para D. João V. Recordaram então que, havia uma década, tinham já recorrido a Sua Majestade para que este "[...] vzasse de sua piedade com aquelles mizeraveis vassallos em os mandar transportar para as costas dos Brasiz". Todavia, não obstante a promessa do monarca, nada se concretizara: João Machado Goulart requeria sobre este assunto havia dez anos e os casais do Pico estavam "padecendo mares de mizeria" 34 . Uma vez mais, os naturais das ilhas invocavam a sua pobreza, pedindo que a piedade régia retirasse 500 casais do Pico, e novamente o Conselho Ultramarino se pronunciou a favor da ocupação dos territórios 
brasileiros com menor densidade de ocupação. No entanto, a piedade do rei só poderia manifestar-se por meio da sua liberalidade, que, neste caso, precisava de financiamento, que não existiu. Assim, face ao fracasso da iniciativa, a coroa suspendeu temporariamente o projecto de transportar casais dos Açores para o Brasil.

No início da década de 1730, a disputa em torno do controlo da bacia do Prata atravessava uma fase de relativo adormecimento, após o episódio da ocupação do sítio de Montevidéu pelos Portugueses, em 1723, que terminou em 1725. Dez anos mais tarde, em 1735 , teve lugar um reacender das hostilidades, que se manteriam até 1737 , período esse durante o qual a colónia do Sacramento esteve cercada ${ }^{35}$. A Convenção de Paris de 15 de Março de 1737 permitiu declarar o fim das hostilidades na América do Sul, mas, no mesmo ano, Portugal reforçou a sua presença na região sul do Brasil, contra a oposição espanhola, com a fundação do presídio do Rio Grande pelo brigadeiro e engenheiro-militar José da Silva Pais, responsável pelas obras de defesa do Rio de Janeiro ao Rio da Prata. Foi igualmente este oficial quem assegurou a defesa da ilha de Santa Catarina, quando esta, juntamente com o Rio Grande, foi separada da capitania de São Paulo, ficando os dois territórios na dependência jurisdicional da capitania do Rio de Janeiro ${ }^{36}$.

A monarquia bourbónica não conseguiu responder à iniciativa portuguesa no Brasil meridional, pois a atenção de Filipe V e dos seus ministros estava orientada para a ameaça de uma nova guerra contra a potência naval britânica. O conflito, que ficou conhecido como a Guerra da Orelha de Jenkins, deflagrou em 1739 e confundiu-se com a Guerra de Sucessão da Áustria (1740-1748). Portugal, escudando-se nos tratados de 1703, optou por manter uma posição neutral, que permitiu a $\mathrm{D}$. João $\mathrm{V}$ evitar o desvio de meios humanos e materiais para um cenário que não lhe interessava.

Em 1738, foi criada a capitania de Santa Catarina, na dependência da do Rio de Janeiro, e José da Silva Pais foi nomeado para o respectivo governo. Tendo visitado a região e constatado que o povoamento era débil, colocando, por isso, problemas no tocante à defesa da ilha de Santa Catarina e do litoral, em 1742, o brigadeiro escreveu a D. João V, defendendo que a presença de casais das ilhas em Santa Catarina era necessária para a conservação de todo o espaço 
Da periferia insular às fronteiras do Império...

geoestratégico sul-brasileiro ${ }^{37}$. Também o Conselho Ultramarino, onde tinham assento ministros conhecedores dos negócios do Brasil, como o desembargador Rafael Pires Pardinho ou Alexandre de Gusmão, se pronunciou, em consulta de 30 de março de 1745, a favor do recrutamento de famílias das ilhas, "tão precizas para deffença, e augmento daquelle Estado." 38

Foi com este pano de fundo que, em 1746, os moradores dos Açores, em pedido dirigido ao rei, solicitaram a passagem aos sertões que se achavam desertos, articulando os argumentos da existência nas ilhas de uma "grande multidão de povo que nelas se acha sem emprego nem meios para subsistir e a necessidade que ha de povoadores para o Brasil" " ${ }^{39}$. Nos Açores, as crises cerealíferas sucediam-se com alguma frequência e atingiam, com diferentes ritmos, as várias ilhas; além disso, eram geralmente acompanhadas de fomes e doenças. Deste modo, para as populações de mais parcos recursos, a emigração surgia como uma forma de fuga a estas situações.

Ora, nesses anos, Portugal negociava com a Espanha os limites entre os territórios sul-americanos de ambas as monarquias, processo que conduziria à assinatura do Tratado de Madrid, em 1750, pelo que o projecto dos açorianos se revelava de grande utilidade, respondendo aos objectivos estratégicos da coroa portuguesa. Iniciou-se então um período de grande intensidade emigratória que se estendeu ao longo de vários anos e que foi estudado em profundidade por Walter F. Piazza e Avelino de Freitas de Meneses ${ }^{40}$.

Após a representação dos ilhéus, o Conselho Ultramarino pronunciou-se favoravelmente quanto à proposta, em consulta datada de 8 de agosto de 1746 . Os conselheiros sublinharam a manifesta utilidade e importância do transporte dos casais em matéria de defesa e de finanças, propondo o recurso a empréstimos para garantir a deslocação de 4.000 casais, à razão de 50.000 réis por unidade familiar, e sugerindo a publicação de editais nas ilhas, que poderiam ir acompanhadas por uma recomendação da Secretaria de Estado da Marinha e do Ultramar - a "secretaria de estado das conquistas" - no sentido de se executarem as ordens do Conselho Ultramarino, apesar dos Açores não estarem sob a jurisdição deste órgão ${ }^{41}$. 
Em 1746 e 1747, foram emitidas ordens para o corregedor dos Açores contendo as disposições que deviam ser seguidas no alistamento dos casais; o regimento que organizava o transporte foi distribuído pelas autoridades; e o Conselho Ultramarino elaborou um "lembrete" relativo ao modo como os casais deviam instalar-se e procurou coordenar a actuação entre os ministros régios nas ilhas e no $\mathrm{Brasi}^{42}$. O transporte foi arrematado a diversos homens de negócio, destacando-se o nome de Feliciano Velho de Oldenberg ${ }^{43}$, e o primeiro contingente de casais partiu dos Açores em Outubro de 1747 , aportando em território brasileiro no início de Janeiro do ano seguinte ${ }^{44}$.

O intenso fluxo migratório que se iniciou no final do reinado de D. João $\mathrm{V}$ foi um movimento controlado pela monarquia portuguesa, que regulamentou a saída dos ilhéus e disciplinou a sua fixação em território brasileiro, quer na Amazónia - Pará e Maranhão quer, sobretudo, na região dos actuais Estados de Santa Catarina e do Rio Grande do Sul. No que respeita ao estado e à condição social, partiram essencialmente casais, mas também indivíduos solteiros de ambos os sexos, de humildes recursos, pobres ou no limiar da pobreza, entre os quais encontramos lavradores, cavadores, trabalhadores e oficiais mecânicos. Quanto ao número dos que partiram para o Brasil, o total exacto de indivíduos não recolhe a unanimidade dos autores. Em 1747, entre casais e solteiros, estavam alistadas cerca de 8.000 pessoas de várias ilhas, como se pode comprovar pela consulta do Quadro 1. 
Da periferia insular às fronteiras do Império...

\section{Quadro $1^{45}$ - Distribuição por ilhas dos alistados para o Brasil (1747)}

$\begin{array}{ccccc} & \text { ILHAS } & \text { HABITANTES } & \text { ALISTADOS } & \% \\ & \text { São Miguel } & 54.670 & 328 & 0,60 \\ \mathbf{N} & \text { Terceira } & 26.433 & 919 & 0,48 \\ & \text { Graciosa } & 8.037 & 771 & 0,59 \\ & \text { São Jorge } & 13.995 & 2.820 & 0,15 \\ & \text { Pico } & 20.639 & 1.816 & 0,80 \\ & \text { Fatal } & 16.669 & 1.287 & 0,72 \\ & \text { AÇORES } & 151.573 & 7.941 & 0,24\end{array}$

O destaque vai para São Jorge, onde mais de $1 / 5$ da população se dispunha a procurar novas oportunidades no espaço brasileiro, e, com menor importância, para as ilhas Graciosa, Pico e Faial. Cerca de uma década mais tarde, em 1756, de acordo com um mapa das freguesias de Santa Catarina, os casais das ilhas que aí residiam eram 1.084, num total de 3.421 pessoas. Em termos globais, cálculos recentes situam a perda de efectivos populacionais do arquipélago em cerca de 5,25\% da população, o que não deixou de ser considerável, sobretudo se considerarmos a saída de gente jovem, pelo que é fácil entender como este surto migratório condicionou a evolução demográfica de algumas ilhas nas décadas de 1760 e $1770^{46}$.

A emigração açoriana com destino ao Brasil continuou ao longo da segunda metade de Setecentos, apesar da lei de 4 de Julho de 1758, com aplicação restrita aos arquipélagos dos Açores e da Madeira, que procurou limitar a saída das populações insulares. Estas movimentações ocorreram paralelamente a outras registadas em diversas zonas do reino, em especial no Minho, mas a saída dos açorianos, sobretudo aquela que foi fomentada pela coroa na segunda metade do século XVIII, teve a particularidade de ser uma emigração essencialmente baseada em levas de recrutas e já não em casais, perante a necessidade de se defender e fixar a fronteira platina nas décadas posteriores à assinatura do Tratado de Madrid ${ }^{47}$. Devemos salientar que a movimentação de açorianos do sexo masculino e em idade activa para o exercício militar assumiu contornos de uma 
verdadeira emigração, com características próprias que influíram no movimento natural dos ilhéus. As suas repercussões tiveram igualmente um efeito adverso na estrutura socioeconómica, que se ressentiu da falta de mão de obra masculina em idade activa.

Em 1766, foram recrutados na ilha de São Miguel 200 homens, que seguiram para o Rio de Janeiro. Sobre o método de recrutamento adoptado, o sargento-mor de São Miguel, António Borges de Bettencourt, referiu que os candidatos, entre os quais se contavam filhos de elementos das governanças nobres da ilha, "forão concorrendo voluntariamente thé se prefazer o numero". A esse propósito, acrescentou ainda

[...] que se mayor fora mais gente avia voluntaria, desta escolhi a melhor e todos os rapazes que poucos excedião a idade de 24 annos com os quais julgo se daria por satisfeito o Excelentissimo Conde da Cunha, porque sertamente herão avultados, e bem figurados os ditos soldados, que sem discomodo antes com utilidade da jlha pela muita gente que tem, se podião repetir as levas ${ }^{48}$.

Os voluntários chegaram ao Rio de Janeiro a 9 de agosto de 1766, na charrua Nossa Senhora da Conceição. Sobre esta recruta, o conde da Cunha, vice rei e capitão general do mar e terra do Estado do Brasil, escreveu a 10 de setembro que

[...] por serem todos voluntarios, de boas figuras, e desembaraço, hé muito propria para o ministerio a que vem destinada. A dita Recruta tem aprendido o Manejo com gosto, e brevidade; e parece me que entre elles vem alguns, que poderão vir a ser officiaes, por serem filhos de pessoas nobres, e tão bem doutrinados, que se fazem distinguir entre os mais. ${ }^{49}$

Concluía o vice rei que era necessário fazer se outro recrutamento,

[...] não só porque já nesta Capitania se não podem fazer muitos Soldados, mas tambem porque quazi todos os Soldados

Anos 90, Porto Alegre, v. 17, n. 32, p. 17-43, dez. 2010 
Da periferia insular às fronteiras do Império...

do tempo de meo Antecessor são já de mayor idade, cazados, cheyos de filhos, e achaques, sendo estes os melhores, que a Tropa tinha. ${ }^{50}$

A opinião do conde da Cunha seria reforçada por uma carta do bispo do Rio de Janeiro, frei António do Desterro, datada de 22 de dezembro do mesmo ano, na qual, a respeito de problemas com as ordenações sacerdotais, aquele religioso denunciava que, na cidade, não se achavam "homens moços para recruta das Tropas", em parte devido ao elevado número de clérigos, a maior parte dos quais ociosos ${ }^{51}$.

O recurso à recruta nas ilhas, composta por homens "de boas figuras", era, pois, essencial, tanto mais que, apenas chegados ao Rio de Janeiro, uma parte dos homens era enviada para as praças do Sul, juntamente com outros mancebos, recrutados na colónia. Em setembro de 1766, a cidade do Rio de Janeiro tinha três regimentos, com um total de 2.390 praças, e haviam sido enviados 276 novos recrutas para a ilha de Santa Catarina, 180 para o Rio Grande e 429 para a Colónia do Sacramento ${ }^{52}$. Assim, as autoridades no reino, nas ilhas e no Brasil continuaram voltadas para os Açores e, em particular, para São Miguel de modo a que a formação de novos contingentes militares continuasse a efectivar se. O conde da Cunha, em meados do ano de 1767, reconhecia a importância da recruta insulana ${ }^{53}$, mas estava consciente de que essa não poderia ser a única solução, nomeadamente devido a problemas de ordem económica.

Mas, não obstante as críticas e as dificuldades de mão de obra masculina que se faziam sentir nas ilhas, as levas de militares prolongaram-se durante a segunda metade do século XVIII, com um impacto bastante acentuado sobre as estruturas demográfica e socioeconómica insulares. Anos mais tarde, em ofício de 25 de maio de 1774, Martinho de Melo e Castro escrevia ao capitão general dos Açores, informando que

[...] pelas Relaçoens que V. Senhoria tem mandado a esta Corte, o grande numero de Habitantes que há nessas Ilhas, e que sem prejuizo, mas antes com utilidade dellas, se podem nas mesmas fazer Reclutas, para os Regimentos que guarnecem 
as differentes Capitanias do Brazil; e achando se os da Capitania do Rio de Janeiro com precizão de seiscentas das ditas Reclutas: Hé o mesmo Senhor servido, que logo que V. S.a receber esta, mande deitar Bando, assim nessa Ilha [=Terceira], como na de São Miguel, e nas mais dos Açores ${ }^{54}$.

Relevemos, uma vez mais, a presença do argumento da sobrepopulação: face ao "grande numero de Habitantes que há nessas Ilhas", "sem prejuizo, mas antes com utilidade dellas, se podem nas mesmas fazer Reclutas". Em nome da utilidade pública, a coroa continuava a recorrer às ilhas açorianas como reservatório demográfico.

Neste contexto, o sistema preconizado para o recrutamento assentava no voluntariado. No entanto, "se elles não chegarem aos seiscentos Homens, que são precizos, depois de expirado o referido Termo, mandará V. Senhoria proceder a Prizoens athé preencher o Numero assima indicado" ${ }^{55}$. O regime voluntário apresentava melhores vantagens, podendo os militares requerer a sua demissão depois de cumprirem oito anos de serviço militar; em contrapartida, os que fossem recrutados compulsivamente serviriam nos regimentos sem limitação de tempo, "emquanto Sua Magestade o houver por bem, e não mandar o contrario". O tempo de serviço preconizado equivaleria, em termos práticos, a uma adequação a novas realidades e, talvez, a um posterior "enraízamento" no território onde era desempenhada a sua função. Cremos mesmo que a maioria destes militares que se terão deslocado para o Brasil acabaram por aí se fixar. 
Da periferia insular às fronteiras do Império...

\section{Quadro 2 - Recrutamentos militares nos Açores (Segunda metade do século XVIII)}

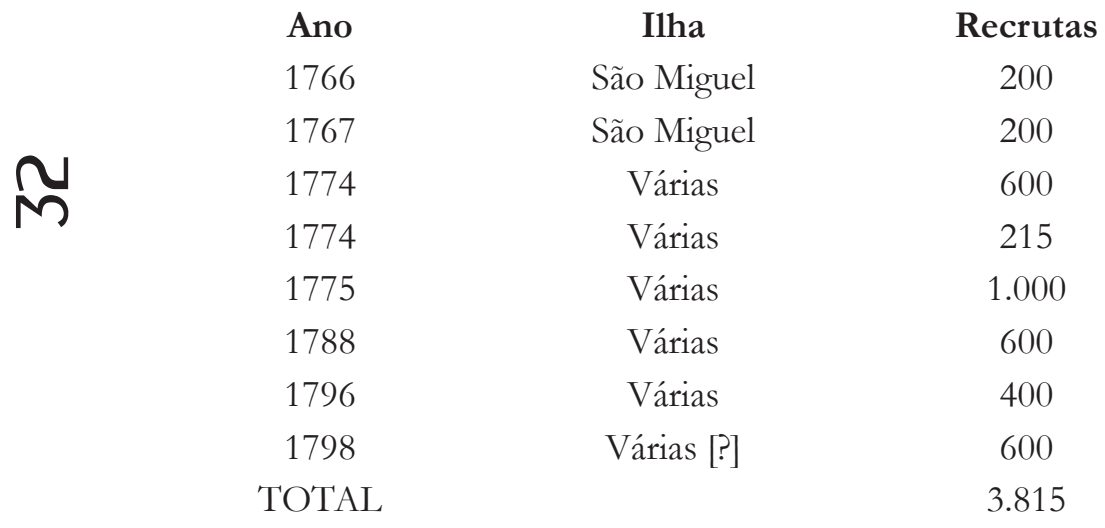

$\mathrm{Na}$ viragem de século, os recrutamentos continuaram a efectuar se, pois, na América do Sul, as ondas de choque dos sucessos ocorridos na Europa tinham forte impacto, em particular no Rio da Prata, "O ponto de encontro por excelência dos impérios ibéricos na América" ${ }^{56}$. Por um lado, surgiram novas iniciativas de colonização, pelo que, por ofício de 19 de outubro de 1799, os governadores interinos dos Açores trataram de responder a um pedido de recruta de sessenta casais de "pessoas robustas" destinadas a um novo estabelecimento que se projectava criar na Baía, processo que continuou no ano seguinte, quando viajaram na fragata Fenix oito casais (64 pessoas) com destino à Baía, mas com passagem por Lisboa ${ }^{57}$. Por outro lado, a conjuntura internacional de inícios de Oitocentos, com o conflito luso-espanhol de 1801, a guerra anglo-francesa e a invasão de Portugal pelo exército napoleónico em 1807, que forçou à transferência da corte portuguesa para o Brasil, levou a que se retomassem os recrutamentos nos Açores. Assim, apesar da resistência das populações insulanas, em 1804 lançou-se um recrutamento de 1.000 indivíduos com destino ao Rio de Janeiro e, em 1809, solicitou-se novamente às autoridades açorianas que recrutassem "com prudencia e modo a que fosse praticavel nesta materia" pelo menos 3.000 mancebos $^{58}$. Na década seguinte, no contexto de uma estratégia de "europeização" da população no território brasileiro,

Anos 90, Porto Alegre, v. 17, n. 32, p. 17-43, dez. 2010 
os avisos de 11 de março de 1811 e de 15 de janeiro de 1813 fizeram público mais dois recrutamentos de casais, sendo que, no caso do segundo aviso, visava-se transportar casais para São Paulo, Rio Grande de São Pedro e Minas, tendo sido a resposta muito positiva: não contando as pessoas singulares, haveria mais oito centenas de pessoas dos casais ${ }^{59}$.

Como corolário de todo este fluxo multissecular, a presença açoriana no Brasil foi-se consolidando. A título de exemplo, refiramos que, em 1801, com base nas listas de habitantes da capitania de São Paulo, 20\% dos homens era oriundo dos Açores, percentagem unicamente ultrapassada pela dos minhotos, com $45 \%{ }^{60}$. A mobilidade tradicional dos açorianos em direcção à América do Sul foi apenas interrompida com os problemas políticos decorrentes da revolução liberal de 1820 e a independência brasileira. $O$ facto de o Brasil se ter tornado um país estrangeiro acarretou novos problemas de circulação. Seria somente na década de 1830, após a guerra civil em Portugal e a implementação de reformas administrativas que recomeçaria a emigração para o Brasil, mas agora com diferenças consideráveis em relação ao passado.

É, pois, evidente a importância desempenhada pelos Açores na colonização do território brasileiro até ao início do século XIX. Se estas movimentações ocorreram em paralelo com outras registadas em diversas zonas do reino, a saída de açorianos teve a particularidade de ser uma emigração estratégica, essencialmente colonizadora e definitiva, sobretudo aquela que se organizou em torno de movimentações familiares, os "casais", ou militares, as "levas". Neste contexto, embora a política dos "casais" tenha sido aplicada também no Amazonas e na Baía, foi sobretudo na fronteira sul-brasileira que o papel dos migrantes açorianos teve um impacto maior e mais duradouro. E, sobre a importância desempenhada pelos Açores na colonização das periferias do vasto território brasileiro ${ }^{61}$, podemos concluir com as palavras finais do romance de Luiz Antônio de Assis Brasil, Um quarto de légua em quadro:

Os ilhéos, huma vez que as Missoens nam se desocuparam, já se accomodam \& alguns athe tornaram-se grandes proprietários \& abastados fazendeiros.

Anos 90, Porto Alegre, v. 17, n. 32, p. 17-43, dez. 2010 
Da periferia insular às fronteiras do Império...

Já nam querem mais voltar para o Archipelago, apezar de jamais esquecerem os padecimentos sem conta que passaram. ${ }^{62}$

From the insular periphery to the imperial borderlands: settlers and soldiers in the peopling of Portuguese America

Abstract: In the Portuguese context, the inhabitants of the Atlantic islands proved to be, more than once, a vital resource for the monarchy in order to people and to defend other peripheral areas of the Portuguese empire. In this article, we present the broad lines of Portuguese settlement in northern (Pará and Maranhão) and southern (Santa Catarina and Rio Grande do Sul) Brazil. This was made with settlers — the "couples" — and soldiers born in the Azores, a process that came to an end only with the independence of Brazil.

Keywords: Atlantic migration. Settlement. Settlers. Soldiers. Brazil. Azores.

\section{Notas}

${ }^{1}$ Cf. Reed Ueda, "Pushing the Atlantic Envelope: Interoceanic Perspectives on Atlantic History", in Jorge Cañizares-Esguerra e Erik R. Seeman (eds.), The Atlantic in Global History, 1500-2000, Upper Saddle River, NJ, Prentice Hall, 2006, pp. 163-175, maxime p. 164 para a citação.

${ }^{2}$ Cf. Fernand Braudel, O Mediterrâneo e o Mundo Mediterrânico na época de Filipe II, $2^{\mathrm{a}}$ ed., Lisboa, Publicações Dom Quixote, 1995, vol. I, pp. 172-174.

${ }^{3}$ Cf. Reed Ueda, "Pushing the Atlantic Envelope: Interoceanic Perspectives on Atlantic History", in Jorge Cañizares-Esguerra e Erik R. Seeman (eds.), The Atlantic in Global History, 1500-2000, Upper Saddle River, NJ, Prentice Hall, 2006, pp. 163-175, maxime p. 164 para a citação.

${ }^{4}$ Cf. John R. Gillis, Islands of the Mind: How the Human Imagination Created the Atlantic World, New York-Basingstoke, Palgrave Macmillan, 2004, p. 99.

${ }^{5}$ Cf. Laura de Mello e Souza e Maria Fernanda Baptista Bicalho, 1680-1720: 0 império deste mundo, "Virando séculos, 4", São Paulo, Companhia das Letras, 2000, pp. 19 e 21.

${ }^{6}$ Sobre o significado destes tratados, ver AAVV, O Tratado de Methuen (1703): diplomacia, guerra, politica e economia, Lisboa, Livros Horizonte, 2003.

${ }^{7}$ Cf. Charles Ralph Boxer, The Golden Age of Brazil: Growing Pains of a Colonial Society 1695-1750, Manchester, Carcanet, 1995 [edição original: 1962], pp. 84-105; Laura de Mello e Souza e Maria Fernanda Baptista Bicalho, ob. cit., pp. 41-61; e

Anos 90, Porto Alegre, v. 17, n. 32, p. 17-43, dez. 2010 
Maria Fernanda Bicalho, A cidade e o império: o Rio de Janeiro no século XVIII, Rio de Janeiro, Civilização Brasileira, 2003, pp. 268-279.

${ }^{8}$ Cf. Biblioteca Nacional de Portugal, Fundo Geral, cod. 512, fl. 162.

${ }^{9}$ Cf. Sebastião da Rocha Pita, História da América Portuguesa, apresentação de Mário Guimarães Ferri, introdução e notas de Pedro Calmon, Belo Horizonte, Editora Itatiaia, 1976, p. 257.

${ }^{10}$ Cf. José Damião Rodrigues e Artur Boavida Madeira, "Rivalidades imperiais e emigração: os açorianos no Maranhão e no Pará nos séculos XVII e XVIII", Anais de História de Além-Mar, Lisboa, vol. IV, 2003, pp. 247-263.

${ }^{11}$ Cf. Francisco Adolfo de Varnhagen, História Geral do Brasil, $5^{\mathrm{a}}$ ed., São Paulo, Edições Melhoramentos, 1956, tomo IV, p. 99, n. 16.

${ }^{12}$ Cf. Biblioteca Pública e Arquivo Regional de Angra do Heroísmo (BPARAH), Arquivo da Câmara de Angra do Heroísmo (ACAH), Livro do Tombo [Registo] (1680 1726), fl. 100, carta régia de 26 de Setembro de 1708; BPARAH, ACAH, Acórdãos, Livro 16 (1706-1714), fl. 113, vereação de 5 de Novembro de 1708; Francisco Ferreira Drummond, Anais da Ilha Terceira, reimpressão fac-similada da edição de 1850 1864, Angra do Heroísmo, Secretaria Regional de Educação e Cultura, 1981, vol. II, p. 229.

${ }^{13}$ Cf. BPARAH, ACAH, Acórdãos, Livro 16 (1706-1714), fls. 100 v-102, consulta de 22 de Setembro de 1708; padre Manuel de Azevedo da Cunha, Notas Históricas, I: Estudos sobre o concelho da Calheta (S. Jorge), recolha, introdução e notas de Artur Teodoro de Matos, Ponta Delgada, Universidade dos Açores, 1981, pp. 463 479; João Gabriel Ávila, "René Duguay Trouin e a invasão de Velas, em 29 de Setembro de 1708", in Dom Frei Bartolomeu do Pilar, Bispo do Grão Pará e Maranhão e outras crónicas, Ponta Delgada, Signo, 1992, pp. 6985.

${ }^{14}$ Cf. BPARAH, ACAH, Acórdãos, Livro 16 (1706-1714), fls. 180 e 186, vereações de 19 de Fevereiro e 8 de Abril de 1710, respectivamente.

${ }^{15}$ Cf. Arquivo dos Açores, edição fac-similada da edição original, Ponta Delgada, Universidade dos Açores, vol. XII, 1983, pp. 460-472, "Carta a El Rey nosso Senhor em que lhe faz relação Antonio do Couto das seis ilhas baixas e da Terceira, anno de 1709", maxime pp. 468 e 470.

${ }^{16}$ Sobre o conceito de "biopolítica", ver as obras clássicas de Michel Foucault, É preciso defender a sociedade. Curso no Collège de France (1975-1976), Lisboa, Editora Livros do Brasil, 2006 [edição original: 1997] e Nascimento da Biopolítica, com Introdução de Bruno Maçães, "Biblioteca de Teoria Política, 5", Lisboa, Edições 70, 2010 [edição original: 2004]. Para a sua aplicação ao universo insular português, ver Cristiana Bastos, "Migrants, Settlers and Colonists: The Biopolitics of Displaced Bodies", International Migration, vol. 46 (5), 2008, pp. 27-54.

${ }^{17}$ Cf. Andreas Osiander, The States System of Europe, 1640-1990. Peacemaking and the Conditions of International Stability, Oxford, Clarendon Press, 1994.

Anos 90, Porto Alegre, v. 17, n. 32, p. 17-43, dez. 2010 
Da periferia insular às fronteiras do Império...

${ }^{18}$ Cf. Jonathas da Costa Rego Monteiro, A Colónia do Sacramento, 1680-1777, Porto Alegre, Globo, 1937, t. 2, p. 61; Joaquim Romero Magalhães, "As novas fronteiras do Brasil", in Francisco Bethencourt e Kirti Chaudhuri (dir.), História da Expansão Portuguesa, vol. III: O Brasil na Balança do Império (1697 1808), Lisboa, Círculo de Leitores, 1998, pp. 10 42, maxime p. 10; Maria Beatriz Nizza da Silva, D. João V, "Reis de Portugal, XXIV", Lisboa, Círculo de Leitores-Centro de Estudos dos Povos e Culturas de Expressão Portuguesa, 2006, p. 210.

${ }^{19}$ Cf. Maria Beatriz Nizza da Silva, ob. cit., pp. 210-211.

${ }^{20}$ Cf. André Ferrand de Almeida, A formação do espaço brasileiro e o projecto do Novo Atlas da América Portuguesa (1713-1748), Lisboa, Comissão Nacional para as Comemorações dos Descobrimentos Portugueses, 2001, pp. 66-72.

${ }^{21}$ Cf. Arquivo Histórico Ultramarino (AHU), Conselho Ultramarino (CU), caixa 2, doc. 30, in Arquivo dos Açores, $2^{a}$ Série, Ponta Delgada, Universidade dos Açores, vol. II, 2001, doc. 31, pp. 184-186.

${ }^{22}$ Idem, p. 186.

${ }^{23}$ Sobre estas movimentações, ver Arquivo dos Açores, $2^{\text {a }}$ Série, vol. II, 2001, docs. 31-38, pp. 184-223, de 31 de Outubro de 1720 a 12 de Fevereiro de 1723, e docs. 40-42, pp. 254-258, de Julho a Dezembro de 1723; Avelino de Freitas de Meneses, Gentes dos Açores: o número e a mobilidade em meados do século XV III, trabalho elaborado no âmbito da prestação de Provas de Agregação, Ponta Delgada, Universidade dos Açores, 1997, policopiado; e, do mesmo autor, "Os Ilhéus na colonização do Brasil: O caso das gentes do Pico na década de 1720", Arquipélago história, Ponta Delgada, 2a Série, vol. III, 1999, pp. 251264.

${ }^{24}$ Cf. AHU, CU, Açores, caixa 2, doc. 33, in Arquivo dos Açores, $2^{a}$ Série, vol. II, 2001, doc. 33, pp. 188-189.

${ }^{25}$ Ibidem.

${ }^{26}$ Cf. AHU, CU, Açores, caixa 2, doc. 36, de 15 de Setembro de 1722, in Arquivo dos Açores, $2^{\text {a }}$ Série, vol. II, 2001, doc. 35, pp. 190-191.

${ }^{27}$ Cf. BPARAH, ACAH, Acórdãos, Livro 17 (1714-1724), fl. 297 v.

${ }^{28}$ Cf. AHU, CU, Açores, caixa 2, doc. 35, in Arquivo dos Açores, $2^{\text {a }}$ Série, vol. II, 2001, doc. 34, p. 189. Sobre os navios do privilégio, ver Maria Olímpia da Rocha Gil, "Os Açores e o comércio Atlântico nos finais do Século XVII (1680-1700)", Arquipélago, Série Ciências Humanas, Número Especial, 1983, pp. 137-204; e José Damião Rodrigues, São Miguel no século XVIII: casa, elites e poder, Ponta Delgada, Instituto Cultural de Ponta Delgada, 2003, vol. I, pp. 150-160.

${ }^{29}$ Cf. AHU, CU, Açores, caixa 2, doc. 34, de 10 e 11 de Novembro de 1722 (lista elaborada a 14 de Agosto de 1722), in Arquivo dos Açores, 2 ${ }^{a}$ Série, vol. II, 2001, doc. 36, pp. 192-201.

Anos 90, Porto Alegre, v. 17, n. 32, p. 17-43, dez. 2010 
José Damião Rodrigues

${ }^{30}$ Cf. AHU, CU, Açores, caixa 2, docs. 37, de 16 de Janeiro de 1723, e 38, de 12 de Fevereiro de 1723, in Arquivo dos Açores, $2^{a}$ Série, vol. II, 2001, docs. 37-38, pp. 201-223, maxime p. 201 para a citação.

${ }^{31}$ Cf. AHU, CU, Açores, caixa 2, doc. 40, in Arquivo dos Açores, $2^{\text {a }}$ Série, vol. II, 2001, doc. 40, pp. 254-256, maxime p. 256 para a citação.

${ }^{32}$ Cf. AHU, CU, Açores, caixa 2, doc. 41, in Arquivo dos Açores, $2^{a}$ Série, vol. II, 2001, doc. 41, pp. 256-258.

${ }^{33}$ Cf. AHU, CU, Açores, caixa 2, doc. 45, de 21 de Julho de 1724, in Arquivo dos Açores, $2^{a}$ Série, vol. II, 2001, doc. 44, p. 259.

${ }^{34}$ Cf. AHU, CU, Açores, caixa 2, doc. 46, de 30 de Outubro de 1729 a 6 de Outubro de 1730, in Arquivo dos Açores, $2^{\text {a }}$ Série, vol. II, 2001, doc. 46, pp. 260-262; e Avelino de Freitas de Meneses, "Os Ilhéus na colonização do Brasil: O caso das gentes do Pico na década de 1720”, loc. cit., pp. 262263.

${ }^{35}$ Cf. Antonio de Béthencourt Massieu, Relaciones de España bajo Felipe V. Del Tratado de Sevilla a la Guerra con Inglaterra (1729-1739), Valladolid-La Laguna-Las Palmas, Universidad de Valladolid-Universidad de La Laguna-Universidad de Las Palmas, 1998, pp. 377-398; Jaime Cortesão, Alexandre de Gusmão e o Tratado de Madrid, "Obras Completas de Jaime Cortesão, XXXI", $2^{\text {a }}$ ed., Lisboa, Livros Horizonte, 1984 [edição original: 1950 1963], vol. II, pp. 551 577; e Luís Ferrand de Almeida, Alexandre de Gusmão, o Brasil e o Tratado de Madrid (1735 1750), "História Moderna e Contemporânea - 5", Coimbra, INIC, Centro de História da Sociedade e da Cultura, Universidade de Coimbra, 1990, pp. 1725.

${ }^{36}$ Cf. Artur Cezar Ferreira Reis, "Pais, José da Silva (século XVIII)", in Joel Serrão (dir.), Dicionário de História de Portugal, s. ed., Porto, Livraria Figueirinhas, 1981, vol. IV, pp. 516-517; Guy Martinière, "A Implantação das Estruturas de Portugal na América (1620-1750)”, in Frédéric Mauro (coord.), O Império Luso Brasileiro 1620 1750, Nova História da Expansão Portuguesa, direcção de Joel Serrão e A. H. de Oliveira Marques, Lisboa, Editorial Estampa, vol. VII, 1991, pp. 91 169, maxime pp. 162163.

${ }^{37}$ Cf. Maria Beatriz Nizza da Silva, ob. cit., p. 213.

${ }^{38}$ Cf. Walter F. Piazza, A epopéia açórico madeirense, 1748 1756, $2^{a}$ ed., revista, Funchal, Centro de Estudos de História do Atlântico, Secretaria Regional do Turismo e Cultura, 1999 [edição original: 1992], pp. 65-66.

${ }^{39}$ Cf. AHU, CU, Açores, caixa 3, doc. 10, de 1 a 8 de Agosto de 1746, in Arquivo dos Açores, $2^{a}$ Série, vol. III, 2005, doc. 10, pp. 23-34, maxime p. 23 para a citação. ${ }^{40}$ Cf. Walter F. Piazza, ob. cit. (cf. supra, nota 38); e Avelino de Freitas de Meneses, Gentes dos Açores: o número e a mobilidade em meados do século XVIII (cf. supra, nota 23). ${ }^{41}$ Cf. AHU, CU, Açores, caixa 3, doc. 10, de 1 a 8 de Agosto de 1746, in Arquivo dos Açores, $2^{\text {a }}$ Série, vol. III, 2005, doc. 10, pp. 23-34, maxime pp. 29-31.

Anos 90, Porto Alegre, v. 17, n. 32, p. 17-43, dez. 2010 
Da periferia insular às fronteiras do Império...

${ }^{42}$ Cf. AHU, CU, Açores, caixa 3, docs. 11, de 31 de Agosto a 5 de Setembro de 1746, 13, de 26 de Junho de 1747, e 14, de 17 de Agosto de 1747, in Arquivo dos Açores, $2^{\text {a }}$ Série, vol. III, 2005, docs. 11, 13 e 14, pp. 34-60.

${ }^{43}$ Cf. AHU, CU, Açores, caixa 3, docs. 15, de 17 de Agosto de 1747 a 11 de Fevereiro de 1756, 21B, anterior a 17 de Junho de 1748, e 53, de 3 de Julho de 1748, in Arquivo dos Açores, $2^{\text {a }}$ Série, vol. III, 2005, docs. 15, pp. 60-68, 24, pp. 86-88, e 26, pp. 91-92.

${ }^{44}$ Cf. Walter F. Piazza, ob. cit., pp. 305-306.

${ }^{45}$ Fonte do Quadro 1: AHU, CU, Açores, caixa 3, doc. 20, in Arquivo dos Açores, $2^{\text {a }}$ Série, vol. III, 2005, doc. 20, pp. 80-81; e Artur Boavida Madeira, População e emigração nos Açores - 1766-1820, Cascais, Patrimonia, 1999, p. 209, Quadro 93.

${ }^{46}$ Sobre as cifras deste fluxo migratório, ver Manuel de Paiva Boléo, Filologia e História. A emigração açoriana para o Brasil (Com documentos inéditos), Coimbra, Edição da Casa do Castelo, Editora, 1945, p. 8; Oswaldo R. Cabral, "Os Açorianos”, in Anais do Primeiro Congresso de História Catarinense, Florianópolis, Imprensa Oficial, 1950, vol. II, pp. 503 608, com documentos; Walter F. Piazza, ob. cit.; Walter F. Piazza e Vilson Francisco de Farias, "O contributo açoriano ao povoamento do Brasil", in Actas da III Semana de Estudos da Cultura Açoriana e Catarinense, Ponta Delgada, 30 Outubro 4 Novembro 1989, Ponta Delgada, Universidade dos Açores, 1993, pp. 191 220, com dados demográficos; e Artur Boavida Madeira, ob. cit..

${ }^{47}$ Sobre esta questão, ver José Damião Rodrigues e Artur Boavida Madeira, "A emigração para o Brasil: As levas de soldados no século XVIII", in Portos, Escalas e Ilhéus no relacionamento entre o Ocidente e o Oriente. Actas do Congresso Internacional Comemorativo do Regresso de Vasco da Gama a Portugal, Ilhas Terceira e S. Miguel, 11 a 18 de Abril de 1999, Lisboa, Universidade dos Açores-Comissão Nacional para as Comemorações dos Descobrimentos Portugueses, 2001, $2^{\circ}$ vol., pp. 109-130. ${ }^{48}$ Cf. AHU, CU, Açores, caixa 5, doc. 49, 5 de Agosto de 1766, in Arquivo dos Açores, $2^{\text {a }}$ Série, vol. IV, 2007, doc. 96, pp. 519-570, maxime p. 519 para a citação (desenvolvemos as abreviaturas).

${ }^{49}$ Cf. AHU, CU, Brasil Rio de Janeiro, caixa 86, doc. 11, 10 de Setembro de 1766.

${ }^{50}$ Ibidem.

${ }^{51}$ Idem, caixa 86, doc. 60, 22 de Dezembro de 1766.

${ }^{52}$ Idem, caixa 86, doc. 19, 16 de Setembro de 1766. A atenção prestada pela coroa portuguesa às questões militares reflectiu se nas medidas levadas a cabo pelo conde da Cunha no ano de 1767, quando, para execução da carta régia de 22 de Março de 1766, mandou alistar todos os moradores da sua jurisdição "que se achassem em estado de servir nas Tropas Auxiliares, sem excepção de Nobres, Plebeos, Brancos, Mistiços, Pretos, Jngenuos, e Libertos", para formar terços de auxiliares e companhias de ordenanças, de infantaria e de cavalaria. Cf. idem, caixa 87 , doc. 24, 4 de Fevereiro de 1767, e doc. 25, com a mesma data.

Anos 90, Porto Alegre, v. 17, n. 32, p. 17-43, dez. 2010 
53 “A percizão que há de Se Completar o numero dos Soldados que São nesseçarios nos tres Regimentos desta Capital, asim Como tambem do da Praça da nova Colonia, no dos Dragões do Rio Grande e nas Seis Companhias que guarnecem Santa Catherina he Constante a Sua Magestade. Por este motivo foy o mesmo Senhor Sertido [sic] mandar no anno procimo paçado Conduzir para esta Terra da das [sic] Jlhas dos Assores, duzentos Homens, e detreminar que no prezente venham outros tantos". Cf. idem, caixa 88, doc. 66, 27 de Julho de 1767.

${ }^{54}$ Cf. AHU, CU, Açores, caixa 10, doc. 4, 25 de Maio de 1774.

${ }^{55}$ Ibidem.

${ }^{56}$ Cf. Andréa Slemian e João Paulo G. Pimenta, A corte e o mundo: uma história do ano em que a família real portuguesa chegou ao Brasil, São Paulo, Alameda, 2008, p. 159.

${ }^{57}$ Cf. AHU, CU, Açores, caixa 30, docs. 30, 19 de Outubro de 1799, e 38, 22 de Outubro de 1799; caixa 32, doc. 13, 8 de Maio de 1800; caixa 34, doc. 12, 23 de Junho de 1800; caixa 40, doc. 3, 4 de Julho de 1801; Francisco Ferreira Drummond, Anais da Ilha Terceira, reimpressão fac-similada da edição de 1850 1864, Angra do Heroísmo, Secretaria Regional de Educação e Cultura, 1981, vol. III, p. 97. ${ }^{58}$ Cf. AHU, CU, Açores, caixa 45, doc. 5, 20 de Fevereiro de 1804; BPARAH, Capitania Geral, Livro $n^{\circ} 3$ do registo das ordens expedidas pelas secretarias de Estado ao governo das ilhas dos Açores, 26 de Abril de 18097 de Maio de 1814, fls. 4v 5, n. 30 e 31, Julho e Novembro de 1809.

${ }^{59}$ Cf. AHU, CU, Açores, caixa 78, doc. 19, 15 de Março de 1813; caixa 81, doc. 21, 14 de Setembro de 1813. Diga-se que, na sequência do aviso de 11 de Março de 1811, a Intendência-Geral da Polícia no Rio de Janeiro concedeu ao influente e rico homem de negócios de São Miguel Nicolau Maria Raposo e aos seus sócios o exclusivo do transporte de passageiros das ilhas açorianas para a América portuguesa e, em 1813, o filho de Nicolau Maria Raposo, com o mesmo nome do pai, conseguiu através de Pedro José Caupers, guarda-roupa do Príncipe Regente, o exclusivo para o transporte de casais dos Açores para o Brasil, com o privilégio de poder escolher os casais. Cf. Carlos Cordeiro e Artur Boavida Madeira, "A emigração açoriana para o Brasil (1541-1820): uma leitura em torno de interesses e vontades", Arquipélago-história, Ponta Delgada, 2 2 Série, vol. VII, 2003, pp. 99-122, maxime p. 116; Maria Margarida de Mendonça Vaz do Rego Machado, Uma fortuna do Antigo Regime: a casa comercial de Nicolau Maria Raposo de Amaral, "Patrimonia Historica", Cascais, Patrimonia, 2005, pp. 97-98.

${ }^{60}$ Cf. Manolo Florentino e Cacilda Machado, "Ensaio sobre a imigração portuguesa e os padrões de miscigenação no Brasil (séculos XIX e XX)", Portuguese Studies Review, 10 (1), 2002, pp. 58-84, maxime p. 59.

Anos 90, Porto Alegre, v. 17, n. 32, p. 17-43, dez. 2010 
Da periferia insular às fronteiras do Império...

${ }^{61}$ Para o século XVII e para a bacia do Amazonas, ver José Damião Rodrigues e Artur Boavida Madeira, "Rivalidades imperiais e emigração: os açorianos no Maranhão e no Pará nos séculos XVII e XVIII", loc. cit..

${ }^{62}$ Cf. Luiz Antônio de Assis Brasil, Um quarto de légua em quadro, s. 1., Direcção Regional das Comunidades-Editora Movimento, s. d. [2005], p. 205.

\section{$\underset{7}{ }$ Referências}

AAVV. O Tratado de Methuen (1703): diplomacia, guerra, política e economia, Lisboa: Livros Horizonte, 2003.

ALMEIDA, André Ferrand de. A formação do espaço brasileiro e o projecto do Novo Atlas da América Portuguesa (1713-1748), Lisboa: Comissão Nacional para as Comemorações dos Descobrimentos Portugueses, 2001.

ALMEIDA, Luís Ferrand de. Alexandre de Gusmão, o Brasil e o Tratado de Madrid (1735 1750), "História Moderna e Contemporânea — 5", Coimbra, INIC, Centro de História da Sociedade e da Cultura, Universidade de Coimbra, 1990.

BÉTHENCOURT MASSIEU, Antonio de. Relaciones de España bajo Felipe V. Del Tratado de Sevilla a la Guerra con Inglaterra (1729-1739). Valladolid-La Laguna-Las Palmas, Universidad de Valladolid-Universidad de La Laguna-Universidad de Las Palmas, 1998.

BICALHO, Maria Fernanda. A cidade e o império: o Rio de Janeiro no século XVIII, Rio de Janeiro: Civilização Brasileira, 2003.

BICALHO, Maria Fernanda. Inflexões na política imperial no reinado de D. João V, Anais de História de Além-Mar, Lisboa-Ponta Delgada, v. VIII, p. 37-56, 2007.

BOLÉO, Manuel de Paiva, Filologia e História. A emigração açoriana para o Brasil (Com documentos inéditos), Coimbra: Casa do Castelo Editora, 1945.

BOXER, Charles Ralph. The Golden Age of Brazil: Growing Pains of a Colonial Society 1695-1750, Manchester: Carcanet, 1995 [edição original: 1962].

BRASIL, Luiz Antônio de Assis. Um quarto de légua em quadro, s. 1., Direcção Regional das Comunidades-Editora Movimento, s. d. [2005]

CABRAL, Oswaldo R. Os Açorianos. In: Anais do Primeiro Congresso de História Catarinense, Florianópolis: Imprensa Oficial, v. II, p. 503 608, 1950.

COATES, Timothy J. Degredados e Órfãs: colonização dirigida pela coroa no império português, 1550-1755, Lisboa, Comissão Nacional para as Comemorações dos Descobrimentos Portugueses, 1998.

Anos 90, Porto Alegre, v. 17, n. 32, p. 17-43, dez. 2010 
José Damião Rodrigues

CORTESÃO, Jaime. Alexandre de Gusmão e o Tratado de Madrid, Obras Completas de Jaime Cortesão, XXXI, $2^{a}$ ed., Lisboa, Livros Horizonte, [edição original: 1950 1963], v. II, 1984.

DARWIN, John. After Tamerlane: The Global History of Empire Since 1405, New York: Bloomsbury Press, 2008.

DRUMMOND, Francisco Ferreira. Anais da Ilha Terceira, reimpressão fac-similada da edição de 1850 1864, Angra do Heroísmo: Secretaria Regional de Educação e Cultura, 1981, 4 vols.

ENGERMAN, Stanley L.; NEVES, João César das. The Bricks of an Empire 1415-1999: 585 years of Portuguese Emigration, The Journal of European Economic History, v. 26, n. 3, p. 473-474, 1997.

FLORENTINO, Manolo; MACHADO, Cacilda. Ensaio sobre a imigração portuguesa e os padrões de miscigenação no Brasil (séculos XIX e XX), Portuguese Studies Review, v. 10, n. 1, p. 58-84, 2002.

GIL, Maria Olímpia da Rocha. O arquipélago dos Açores no século XVII. Aspectos sócio-económicos (1575-1675), Castelo Branco, edição da autora, 1979.

GODINHO, Vitorino Magalhães. A Estrutura da Antiga Sociedade Portuguesa, $4^{a}$ ed., Lisboa: Arcádia, 1980 [edição original: 1971].

MADEIRA, Artur Boavida. População e emigração nos Açores - 1766-1820. Cascais: Patrimonia, 1999.

MARTINIÈRE, Guy. A Implantação das Estruturas de Portugal na América (1620-1750), In: Frédéric Mauro (Coord.). O Império Luso Brasileiro 1620-1750, Nova História da Expansão Portuguesa, direcção de Joel Serrão e A. H. de Oliveira Marques, Lisboa: Editorial Estampa, v. VII, p. 91 169, 1991.

MENESES, Avelino de Freitas de. Gentes dos Açores: o número e a mobilidade em meados do século XVIII. Trabalho elaborado no âmbito da prestação de Provas de Agregação, Ponta Delgada, Universidade dos Açores, 1997 (policopiado).

MENESES, Avelino de Freitas de. Os Ilhéus na colonização do Brasil: O caso das gentes do Pico na década de 1720, Arquipélago história, Ponta Delgada, $2^{a}$ Série, v. III, p. 251 264, 1999.

PIAZZA, Walter F. O Povoamento Açoriano. In: Osvaldo Ferreira de Melo (Coord.). História Sócio-Cultural de Florianópolis, Florianópolis: Clube Doze de Agosto-Editora Lunardelli-IHGSC, p. 53-89, 1991.

PIAZZA, Walter F. A epopéia açórico madeirense, 1748 1756, 2ª ed., revista, Funchal, Centro de Estudos de História do Atlântico, Secretaria Regional do Turismo e Cultura, 1999 [edição original: 1992].

Anos 90, Porto Alegre, v. 17, n. 32, p. 17-43, dez. 2010 
Da periferia insular às fronteiras do Império...

PIAZZA, Walter F.; FARIAS, Vilson Francisco de. O contributo açoriano ao povoamento do Brasil. In: Actas da III Semana de Estudos da Cultura Açoriana e Catarinense, Ponta Delgada, 30 Outubro a 4 Novembro 1989, Ponta Delgada, Universidade dos Açores, p. 191-220, 1993.

REIS, Arthur Cezar Ferreira. A Expansão Portuguêsa na Amazônia nos Séculos XVII e XVIII, Colecção Pedro Teixeira, Rio de Janeiro, SPVEA, 1959.

REIS, Artur Cezar Ferreira. Pais, José da Silva (século XVIII), In: Joel Serrão (Dir.), Dicionário de História de Portugal, s. ed., Porto: Livraria Figueirinhas, v. IV, p. 516-517, 1981.

ROCHA, Gilberta Pavão Nunes; RODRIGUES, José Damião; MADEIRA, Artur Boavida; MONTEIRO, Albertino. O arquipélago dos Açores como região de fronteira, Arquipélago-história, Ponta Delgada, 2 2 Série, v. IX-X, 2005-2006, p. $105-140$

RODRIGUES, José Damião. Os Açores e a Expansão: bens e gentes no espaço colonial português (séculos XV-XVIII), Insulana, Ponta Delgada, v. XLIX, p. 147-181, 1993.

RODRIGUES, José Damião. Das ilhas ao Atlântico Sul: a política ultramarina e a emigração açoriana para o Brasil no reinado de D. João V. Anais de História de Além-Mar, Lisboa-Ponta Delgada, v. VIII, p. 57-68, 2007.

RODRIGUES, José Damião; MADEIRA, Artur Boavida. A emigração para o Brasil: As levas de soldados no século XVIII. In: Portos, Escalas e Ilbéus no relacionamento entre o Ocidente e o Oriente. Actas do Congresso Internacional Comemorativo do Regresso de Vasco da Gama a Portugal, Ilhas Terceira e S. Miguel, 11 a 18 de abril de 1999, Lisboa, Universidade dos Açores-Comissão Nacional para as Comemorações dos Descobrimentos Portugueses, 2001, $2^{\circ}$ vol., p. 109-130

RODRIGUES, José Damião; MADEIRA, Artur Boavida, Rivalidades imperiais e emigração: os açorianos no Maranhão e no Pará nos séculos XVII e XVIII, Anais de História de Além-Mar, Lisboa, v. IV, p. 247-263, 2003.

RUSSELL-WOOD, A. J. R. A World on the Move: The Portuguese in Africa, Asia, and America, 1415 1808, Manchester, Carcanet Fundação Calouste Gulbenkian, 1992.

SALOMON, Marlon. O exílio da desordem e a segurança da Ilha de Santa Catarina no século XVIII. In: Ana Brancher e Silvia Maria Fávero Arend (Org.).

Anos 90, Porto Alegre, v. 17, n. 32, p. 17-43, dez. 2010 
José Damião Rodrigues

História de Santa Catarina: séculos XVI a XIX, Florianópolis: Editora da UFSC, p. 79-92, 2004.

SANTOS, Corcino Medeiros dos. Economia e Sociedade do Rio Grande do Sul (Século XV III), Brasiliana, 379, São Paulo-Brasília: Companhia Editora Nacional-Instituto Nacional do Livro, 1984.

SILVA, Maria Beatriz Nizza da. D. João V, Reis de Portugal, XXIV, Lisboa: Círculo de Leitores-Centro de Estudos dos Povos e Culturas de Expressão Portuguesa, 2006.

SOUZA, Laura de Mello e; BICALHO, Maria Fernanda Baptista. 1680-1720: o império deste mundo, Virando séculos, 4, São Paulo: Companhia das Letras, 2000.

VERÍSSIMO, Erico. O tempo e o vento [parte I]: O Continente, v. I, $3^{\text {a }}$ ed., $6^{\text {a reimpr., }}$ São Paulo: Companhia das Letras, 2004 [edição original: 1949]

Recebido em 01/12/2010

Aprovado em 30/01/2011

Anos 90, Porto Alegre, v. 17, n. 32, p. 17-43, dez. 2010 